\title{
Studies on the Q175 knock-in model of Huntington's disease using functional imaging in awake mice: evidence of olfactory dysfunction
}

\author{
Craig F. Ferris $^{1}{ }^{*}$, Praveen Kulkarni ${ }^{1}$, Steven Toddes ${ }^{2}$, Jason Yee ${ }^{1}$, William Kenkel ${ }^{1}$ and Mark Nedelman ${ }^{3}$ \\ ${ }^{1}$ Center for Translational Neurolmaging, Northeastern University, Boston, MA, USA \\ ${ }^{2}$ Animal Imaging Research, Holden, MA, USA \\ ${ }^{3}$ Ekam Imaging, Boston, MA, USA
}

\section{Edited by:}

Marc Dhenain, Commissariat à

I'Énergie Atomique, France

\section{Reviewed by:}

Kimberly Scearce-Levie, Genentech, Inc., USA

Emmanuel Brouillet, Commissariat à I'Énergie Atomique and CNRS, France

*Correspondence:

Craig F. Ferris, Department of

Psychology, Center for Translational

Neurolmaging, Northeastern

University, Boston, MA 02115-5000,

USA

e-mail:c.ferris@neu.edu
Blood oxygen level dependent (BOLD) imaging in awake mice was used to identify differences in brain activity between wild-type, HETzQ175, and HOMzQ175 genotypes in response to the odor of almond. The study was designed to see how alterations in the huntingtin gene in a mouse model of Huntington's disease would affect the perception and processing of almond odor, an evolutionarily conserved stimulus with high emotional and motivational valence. Moreover, the mice in this study were "odor naïve," i.e., never having smelled almond or any nuts. Using a segmented, annotated MRI atlas of the mouse and computational analysis, 17 out of 116 brain regions were identified as responding differently to almond odor across genotypes. These regions included the glomerulus of the olfactory bulb, forebrain cortex, anterior cingulate, subiculum, and dentate gyrus of the hippocampus, and several areas of the hypothalamus. In many cases, these regions showed a gene-dose effect with $\mathrm{HETzQ} 175$ mice showing a reduction in brain activity from wild-type that is further reduced in $\mathrm{HOMzQ} 175$ mice. Conspicuously absent were any differences in brain activity in the caudate/putamen, thalamus, CA3, and CA1 of the hippocampus and much of the cortex. The glomerulus of the olfactory bulb in $\mathrm{HOMzO} 175$ mice showed a reduced change in BOLD signal intensity in response to almond odor as compared to the other phenotypes suggesting a deficit in olfactory sensitivity.

Keywords: BOLD fMRI, neural pathways, reward processing, awake animal imaging, mouse model of Huntington's disease, huntingtin-associated protein 1, feeding behavior

\section{INTRODUCTION}

Huntington's disease (HD) is characterized by motor dysfunction and cognitive decline, and is caused by an autosomal dominant expansion of CAG repeats in the huntingtin (HTT) gene. HD patients often present with non-motor symptoms that include cognitive dysfunction $(1,2)$, affective disorders (3), and sleep and circadian rhythm disruptions, which can all precede the onset of motor dysfunction. In a recent imaging study, Enzi and coworkers reported deficits in reward processing in pre-manifest (near but not symptomatic) HD patients (4). Here, we use awake animal imaging to study the emotional and cognitive neural circuits involved in reward processing in a pre-symptomatic transgenic mouse model of HD. Indeed, with non-invasive ultra-high field, functional magnetic resonance imaging (fMRI) in awake animals, it is possible to image changes in brain activity across distributed, integrated neural circuits with high temporal and spatial resolution (5). When combined with the use of 3D segmented, annotated, brain atlases, and computational analysis it is possible to reconstruct the neural circuits involved in emotional and cognitive processes.

To this end, we report here, for the first time, the development and application of tools for blood oxygen level dependent (BOLD) imaging in awake mice without any invasive surgical preparation. This new technology was applied to the study of the zQ175 knock-in mice containing a human mutant $(\mathrm{mHtt})$ allele with the expanded CAG repeat ( 179 repeats) within the native mouse huntingtin gene (6). This animal model is representative of HD in humans from genetic, neural, and behavioral aspects. Both homozygous (HOM) and heterozygous (HET)zQ175 mice exhibit first signs of motor symptoms from 3 to 4 months of age and behavioral deficits accompanied by marked brain atrophy and brain metabolite changes by 8 months $(6,7)$. Indeed, the knock-in mouse models of HD show disease progression in the HET genotype as protracted and more subtle than HOM providing a better opportunity to identify biomarkers of early neuropathology prior to the onset of motor dysfunction (6-9).

The present studies were conducted on year old wild-type, HET zQ175, and HOM zQ175 mice. We show here that there are significant differences in brain activity in response to the smell of a highly desirable food - almond. In this study, all animals were "odor naïve" to this evolutionarily conserved stimulus (10) raising the following question. How has this single gene mutation altered the perception of this highly important odorant signal? The technology and approach used in this study addresses this question by showing that imaging awake mice is technically feasible and that the BOLD signal changes are robust and provide 
the means of differentiating brain activity between genotypes to an olfactory stimulus that carries high emotional and motivation valence. When these BOLD signal changes are registered to an MRI based, 3D segmented annotated mouse brain atlas, it is possible to identify the integrated neural circuits affected by this single gene mutation.

\section{MATERIALS AND METHODS ANIMAL CARE}

Wild-type mice (C57B/L6J) ( $n=5$ male, 6 female) and knockin zQ175 HET ( $n=4$ male, 6 female) and HOM $(n=5$ male, 5 female) mice (courtesy of Psychogenics Inc., Tarrytown, NY, USA) were maintained on a 12:12 h light:dark cycle with a lights on at 07:00 hours. All mice from each phenotype were born between 16 and 18 August 2011 and scanned $\sim 1$ year later. Animals were allowed access to food and water ad libitum. All the mice were housed in groups of up to four per cage with mice of the same genotype and gender. Mice were cared for in accordance with the guidelines published in the Guide for the Care and Use of Laboratory Animals (National Institutes of Health Publications No. 85-23, Revised 1985) and adhered to the National Institutes of Health and the American Association for Laboratory Animal Science guidelines. The protocols used in this study were in compliance with the regulations of the Institutional Animal Care and Use Committee at Northeastern University.

\section{AWAKE MOUSE IMAGING SYSTEM}

Presented in Figure 1 are the different components of the mouse imaging system showing a radiofrequency coil and MR compatible restraining system for imaging awake or anesthetized mice ranging in the size from 10 to $50 \mathrm{~g}$ (Animal Imaging Research, Holden, MA, USA). The quadrature transmit/receive volume coil (ID $38 \mathrm{~mm}$ ) provides excellent anatomical resolution and signal-noise-ratio for voxel-based fMRI. The unique design of the holder essentially stabilizes the head in a cushion, minimizing any discomfort normally caused by ear bars and pressure points used to immobilize the head for awake animal imaging. The mouse holder can be inserted and withdrawn while the volume coil is positioned in the magnet greatly reducing the set-up time between studies. A movie showing the set-up of a mouse for awake imaging is available at http://www.youtube.com/watch?v=W5Jup13isqw.

It should be noted, Desai and colleagues used BOLD imaging and optogenetics to study integrated neural circuits in awake mice (11). Their experimental design required that each animal be implanted with a head post. In our system, this is not necessary, eliminating the confound of surgery. Moreover, following acclimation it is possible to image multiple animals during an imaging session. The data presented on motion detection in Figure 2 were gathered from 29 mice imaged over a $8 \mathrm{~h}$ period. This was possible because the total scan time (tripilot, anatomy, and functional) was $<15$ min each. In addition, once the quadrature transmit/receive volume coil was position in the magnet, tuned, and matched, it was never moved or adjusted. One mouse holder (see Figure 1) was simply replaced with a second as noted above.

One limitation in the mouse imaging system is the presentation of visual and auditory stimuli. While it is possible to inject drugs (IP, SC, and IV), electrically stimulate fore and hind paws, and run flexible fiber optics to the head through portals in the body tube, the eyes are not easily accessible to visual stimuli. The auditory canal of the ears is blocked by the cushioned head pad, dampening, if not eliminating, auditory stimuli. However, the presentation of odors is actually facilitated by the design of the head holder. The front incisors of the mouse are locked onto a bite bar by pulling the snout into a beveled nose cone. The cone is perforated so as not to restrict the flow of air from the nostrils or mouth. A hollow tube extends from the tip of the nose cone providing a route for administering volatile anesthetics, e.g., isoflurane, carbon dioxide gas as shown in Figure 3 or odors that carry emotional and/or cognitive messages. Furthermore, olfaction is an especially important sensory modality in rodents.

\section{ACCLIMATION AND MOTION DETECTION}

A week prior to the first imaging session, all animals were acclimated to the imaging system before scanning. Animals were secured into their holding system while anesthetized with $2-3 \%$ isoflurane. Following cessation of isoflurane, fully conscious mice were put into a "mock scanner" (a black box with a tape recording of MRI pulses) for $30 \mathrm{~min}$ for four consecutive days. Acclimation in awake animal imaging significantly reduces physiological effects of the autonomic nervous system including heart rate, respiration, corticosteroid levels, and motor movements (12) helping to improve contrast-to-noise and image quality. In these studies, motion artifact was greatly reduced as shown in the time-course data in Figure 2 as estimated by a 3D rigid body model with 6 degrees of freedom for translational and rotational movement. Data were collected from 29 awake mice imaged for $5 \mathrm{~min}$. The average motion is $<20 \mu$.

\section{IMAGING ACOUISITION AND PULSE SEQUENCE}

Experiments were conducted using a Bruker Biospec 7.0 T/20-cm USR horizontal magnet (Bruker, Billerica, MA, USA) and a 20$\mathrm{G} / \mathrm{cm}$ magnetic field gradient insert $(\mathrm{ID}=12 \mathrm{~cm}$ ) capable of a $120-\mu$ s rise time (Bruker). At the beginning of each imaging session, a high-resolution anatomical data set was collected using the RARE pulse sequence ( 20 slice; $0.75 \mathrm{~mm}$; FOV $2.5 \mathrm{~cm}$; data matrix $256 \times 256$; TR $2.1 \mathrm{~s}$; TE $12.4 \mathrm{~ms}$; Effect TE $48 \mathrm{~ms}$, NEX 6; $6.5 \mathrm{~min}$ acquisition time). Functional images were acquired using a multislice half Fourier acquisition single shot turbo spin echo (HASTE) pulse sequence. With this sequence it is possible to collect 20, $0.75 \mathrm{~mm}$ thick, axial slices in $<6 \mathrm{~s}$. With a FOV of $2.5 \mathrm{~cm}$ and a data matrix of $96 \times 96$, the in-plane pixel functional resolution for these studies was $260 \mu \mathrm{m}^{2}$.

The major advantage to a spin echo pulse sequence is its tolerance to magnetic susceptibility and motion artifact. The $180^{\circ}$ RF refocusing pulse corrects for the lack of field homogeneity, chemical shift, tissue artifacts, and magnetic susceptibility from static dephasing in BOLD imaging. The disadvantage is loss of signal contrast. The problem of sensitivity can be addressed with higher field strengths where the BOLD signal becomes a function of dynamic dephasing from diffusion of water at the level of the capillaries $(13,14)$. Using multi-slice, fast spin echo sequences the signal contrast with BOLD imaging is a function of T2 and not $\mathrm{T} 2{ }^{\star}$ at high field strengths. The extravascular signal surrounding capillary beds and small vessels is more reflective of the metabolic 


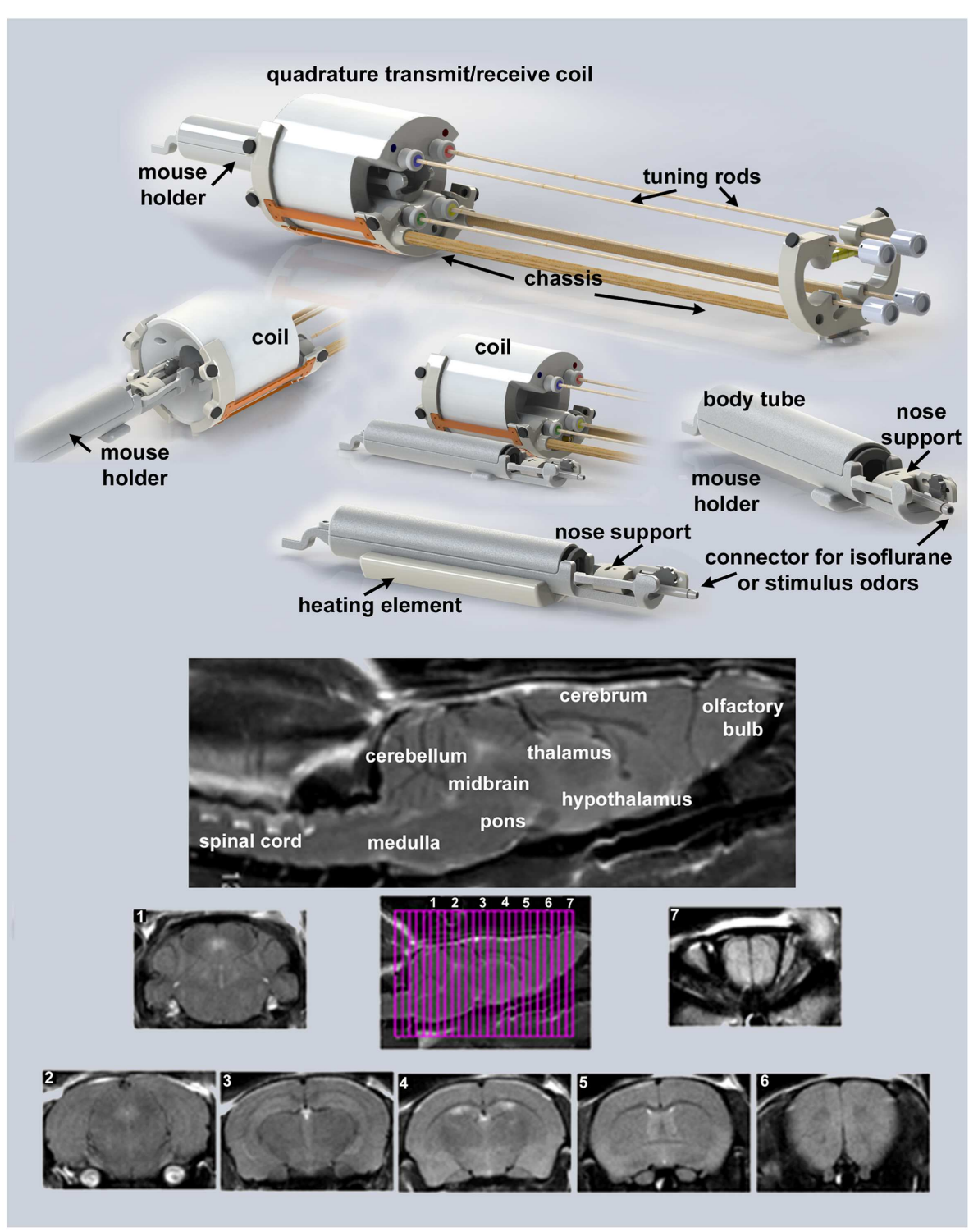

FIGURE 1 | Mouse imaging system. Shown are the different components of the mouse imaging system. Below are sagittal and axial views of an awake mouse brain. Note the linearity along the $Z$-axis. The axial images taken from a 22-slice RARE sequence (0.6 mm thickness) demonstrate complete brain coverage from the olfactory bulbs to the brainstem. The mouse system was provided by Animal Imaging Research, Holden, MA, USA. changes in brain parenchyma than signal from large draining veins helping to improve the localization of the signal changes (15). The BOLD signal is linear and reproducible at stimulus intervals of $1 \mathrm{~s}$ (16).

\section{PROVOCATION PARADIGM - ODOR STIMULANT}

Awake wild-type and transgenic mice were imaged for changes in BOLD signal intensity in response to the odor of almond (benzaldehyde), a stimulus to elicit the innate reward response (10). All animals were "odor naïve" to this evolutionarily conserved stimulus. We chose the almond odor because nuts are high in calories and convey greater valance as compared to the other odors. Moreover, the standard food chow is devoid of nuts, so laboratory bred mice and the mice used in these studies have no previous exposure to this food. In a recent study (10), brain activation maps from the odors of banana, rose, citrus, and almond were dramatically different. Almond but not the other odors activated the hippocampus, amygdala, and limbic cortex. In a serial dilution study for almond scent, we identified a threshold dilution of $100 \%$ benzaldehyde $(1 / 10,000 \mathrm{v} / \mathrm{v})$ that gives a significant and consistent pattern of brain activity. This threshold dilution of almond odor was used in this study. The time series for changes in BOLD signal following presentation of almond odor were analyzed using a repeated measures ANOVA followed by Fisher's protected least significant difference to limit experiment-wise error when performing pairwise comparisons between genotypes. 


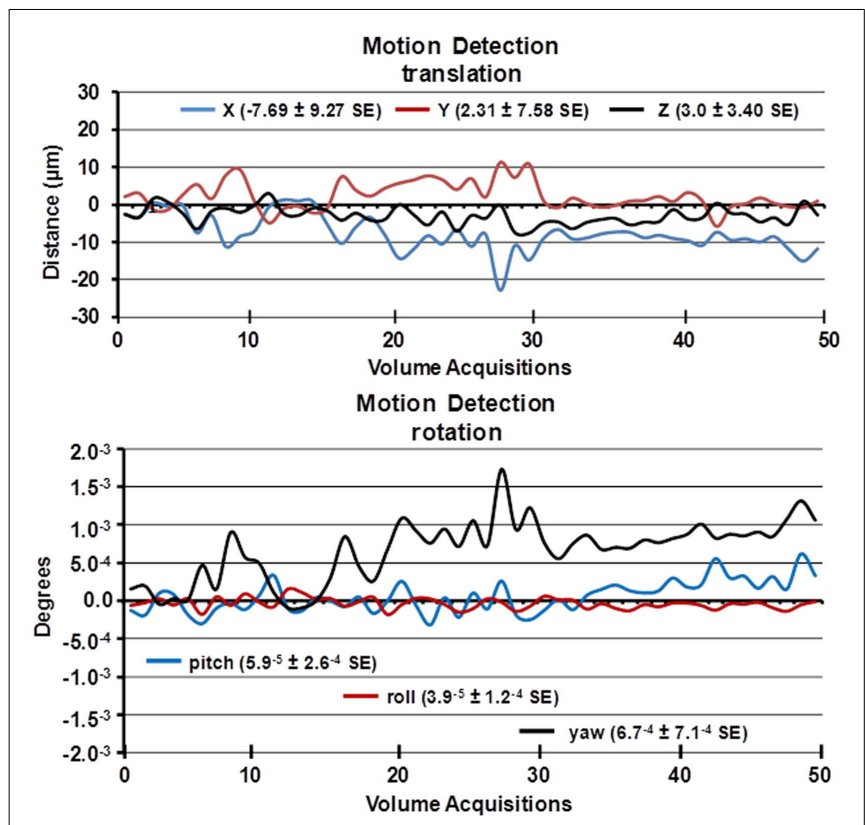

FIGURE 2 | Motion detection following acclimation. Time-course date for motion detection from 29 awake mice imaged for $5 \mathrm{~min}$ is shown. Two and a half minute into the scanning session, mice were challenged with $5 \%$ carbon dioxide (see Figure 3). The data stability were estimated by a 3D rigid body model with 6 degrees of freedom for translational and rotational movement.

\section{DATA ANALYSIS}

Images were aligned and registered to a $3 \mathrm{D}$ mouse brain atlas, which is segmented and labeled with 116 discrete anatomical regions (Ekam Solutions, Boston, MA, USA). The alignment process was facilitated by an interactive graphic user interface. The registration process involved translation, rotation, and scaling independently and in all three dimensions. Matrices that transformed each subject's anatomy were used to embed each slice within the atlas. All pixel locations of anatomy that were transformed were tagged with major and minor regions in the atlas. This combination created a fully segmented representation of each subject within the atlas. The inverse transformation matrix [Ti $]^{-1}$ for each subject (i) was also calculated.

Using voxel-based analysis, the percent change in BOLD signal for each independent voxel was averaged for all subjects. Each scanning session consisted of 70 data acquisitions (whole brain scans) with a period of $6 \mathrm{~s}$ each for a total lapse time of $420 \mathrm{~s}$ or $7 \mathrm{~min}$. The control window was the first 25 scan repetitions ( $2.5 \mathrm{~min}$ baseline) while the odor stimulation window was $26-50$ ( $\min 2.5-5)$. Statistical $t$-tests were performed on each voxel (ca. 15,000 in number) of each subject within their original coordinate system with a baseline threshold of $2 \%$ BOLD change to account for normal fluctuation of BOLD signal in the awake rodent brain (17). As a result of the multiple $t$-test analyses performed, a false-positive detection controlling mechanism was introduced (18). This subsequent filter guaranteed that, on average, the false-positive detection rate was below our cutoff of 0.05 . The $t$-test statistics used a $95 \%$ confidence level, two-tailed distributions, and heteroscedastic variance assumptions.
A composite image of the whole brain representing the average of all subjects was constructed for each group for ROI analyses, allowing us to look at each ROI separately to determine the BOLD change and the number of activated voxels in each ROI. Statistical comparisons of different image acquisitions are compared to baseline (see Table 1) using a non-parametric Kruskal-Wallis test statistic followed by a Mann-Whitney $U$-test.

\section{NORMALIZATION OF VOLUME OF ACTIVATION}

The differences BOLD signal change in wild-type, HETzQ175, and HOMzQ175 mice are reported in terms of volume of activation or number of voxels per region of interest (ROI) or brain area. In this study, the brain size across phenotypes can be significantly different (see Table 2) from each other hence the volume of activation is normalized to volume of ROI. By normalizing to volume of activation, we can compare across different phenotypes or within group among different regions. Normalized volume of activation was computed using following formula.

$$
\begin{aligned}
& \text { Normalized number of voxels in ROI } \\
& =\frac{\text { Number of activated voxels in ROI } \times 100}{\text { Total number of voxels in ROI }} .
\end{aligned}
$$

\section{CALCULATING THE VOLUMES OF DIFFERENT BRAIN AREAS}

The volume of each brain area (ROI) was determined from the high-resolution anatomical scan taken at the beginning of each scanning session for each subject. The $3 \mathrm{D}$ segmented atlas provides the precise number of voxels (3D pixels) that combine to fill the volume of each of the 116 ROIs or brain regions. The dimensions of each voxel are calculated from the slice thickness $(0.75 \mathrm{~mm})$, Voxel width (FOV in X direction/Number of voxels in $\mathrm{X}$ direction) and Voxel height (FOV in $\mathrm{Y}$ direction/Number of voxels in Y direction) using the formula - Volume of voxel $=$ voxel width $\times$ voxel height $\times$ slice thickness $[\mathrm{ca}$. $0.097 \mathrm{~mm} \times 0.097 \mathrm{~mm} \times 0.750 \mathrm{~mm}=0.00706 \mathrm{~mm}^{3}$ ]. Total number of voxels in each ROI were multiplied by volume of voxel to compute total volume of brain region.

\section{CARBON DIOXIDE CHALLENGE}

To assess the strength of the BOLD signal in mice using HASTE and to further characterize any differences between wild-type $(n=7)$, HETzQ175 $(n=7)$, and HOMzQ175 $(n=10)$ mice in terms of cerebrovascular reactivity animals were challenged with a $5 \% \mathrm{CO}_{2}$ as a stimulus for a surrogate BOLD response. Carbon dioxide causes a direct relaxation of cerebrovascular smooth muscle, causing a passive dilation with a subsequent increase in cerebral blood flow. To this end, mice were imaged for a total of $5 \mathrm{~min}$ with presentation of $5 \% \mathrm{CO}_{2}$ in ambient air at $2.5 \mathrm{~min}$ into the scanning session. Data were analyzed using a repeated measures ANOVA followed by Fisher's protected least significant difference to limit experiment-wise error when performing pairwise comparisons between genotypes.

\section{RESULTS}

Shown in Table 1 are the positive BOLD signal changes represented as a percentage of the total ROI volume (i.e., number of voxels activated, divided by the total number of voxels in the $3 \mathrm{D}$ volume of interest, times 100) for wild-type, HET, and HOMzQ175 mice 
Table 1 | Volume of activation in response to almond odor.

\begin{tabular}{|c|c|c|c|c|c|c|c|c|c|c|}
\hline \multirow[t]{2}{*}{ Region of interest (ROI) } & \multicolumn{3}{|c|}{ Wild-type } & \multicolumn{3}{|c|}{ Heter zQ175 } & \multicolumn{3}{|c|}{ Homo zQ175 } & \multirow[b]{2}{*}{$p$ Value } \\
\hline & Med & Max & Min & Med & Max & Min & Med & Max & Min & \\
\hline Medial amygdaloid area & 4 & 20 & 0 & 2 & 10 & 0 & 0 & 0 & 0 & 0.002 \\
\hline Ventral medial hypothalamic area & 7 & 68 & 0 & 13 & 33 & 0 & 0 & 0 & 0 & 0.004 \\
\hline Frontal association ctx & 10 & 23 & 3 & 0 & 14 & 0 & 0 & 11 & 0 & 0.006 \\
\hline Subiculum & 3 & 27 & 0 & 1 & 4 & 0 & 0 & 2 & 0 & 0.008 \\
\hline Anterior hypothalamic area & 3 & 27 & 0 & 4 & 14 & 0 & 0 & 0 & 0 & 0.008 \\
\hline Vestibular area & 8 & 62 & 0 & 0 & 8 & 0 & 0 & 3 & 0 & 0.009 \\
\hline Endopiriform area & 4 & 21 & 0 & 0 & 3 & 0 & 0 & 0 & 0 & 0.011 \\
\hline Extended amydala & 1 & 11 & 0 & 0 & 3 & 0 & 0 & 0 & 0 & 0.012 \\
\hline Dentate gyrus & 6 & 32 & 0 & 1 & 7 & 0 & 0 & 4 & 0 & 0.016 \\
\hline Anterior cingulate area & 4 & 28 & 0 & 0 & 8 & 0 & 0 & 3 & 0 & 0.026 \\
\hline Lateral caudal hypothalamic area & 4 & 39 & 0 & 4 & 25 & 0 & 0 & 11 & 0 & 0.026 \\
\hline Lateral posterior thalamic area & 3 & 27 & 0 & 0 & 0 & 0 & 0 & 33 & 0 & 0.027 \\
\hline Primary somatosensory ctx & 4 & 21 & 2 & 4 & 18 & 0 & 0.5 & 5 & 0 & 0.03 \\
\hline Secondary somatosensory ctx & 1 & 14 & 0 & 3 & 6 & 1 & 0 & 4 & 0 & 0.032 \\
\hline Glomerular layer & 6 & 29 & 1 & 3 & 40 & 1 & 0.5 & 10 & 0 & 0.044 \\
\hline Locus ceruleus & 20 & 50 & 0 & 0 & 31 & 0 & 0 & 33 & 0 & 0.045 \\
\hline Principal sensory nucleus trigeminal & 1 & 21 & 0 & 1 & 6 & 0 & 0 & 1 & 0 & 0.048 \\
\hline Medial mammillary area & 23 & 82 & 0 & 3 & 31 & 0 & 0 & 35 & 0 & 0.059 \\
\hline
\end{tabular}

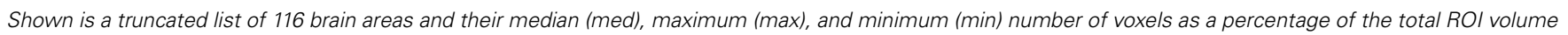

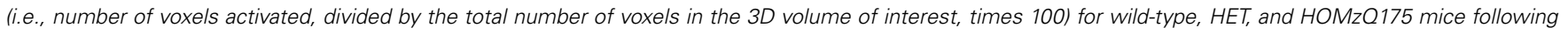

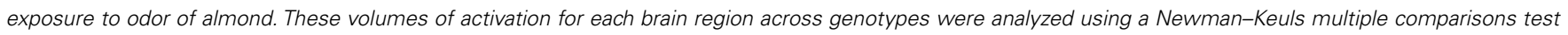

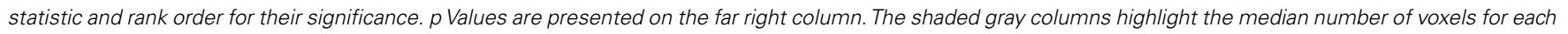
$\mathrm{ROI}$ and each genotype to aid in visual comparisons.

following exposure to odor of almond. The brain areas are rank order for their significance and are truncated from a larger list of 116 regions of activation (for complete list see Table S1 in Supplementary Material). The multiple comparison analysis showed 17 areas to be significantly different across conditions. Using the mouse brain atlas, these 17 brain areas can be reconstructed into a $3 \mathrm{D}$ map as shown in Figure 3. This 3D presentation is the putative neural circuit affected by the huntingtin gene mutation in response to the odor of almond.

The odor of almond elicits an activation pattern across wildtype, HET, and HOMzQ175 mice that suggests a gene-dose effect. The statistical comparisons between conditions and their composite pattern of activation are shown in Figure 4. The bar graphs show the volume of activation as a percentage of the ROI volume for each comparison. The areas of significance are shown in the segmented, 3D color-coded and labeled image above. These 3D areas are coalesced into a single yellow volume to the right showing the location of the average, significant change in BOLD signal. The post hoc analysis shows wild-type to have 14 brain areas that differed in activation from HOMzQ175. These include the forebrain cortical areas (primary somatosensory, frontal association, and anterior cingulate cortices), the hypothalamus (anterior, ventral medial, and lateral caudal areas), the dentate, and subiculum of the hippocampus and the glomerular layer of the olfactory bulbs. When wild-type is compared to HETzQ175 only six areas show a difference in BOLD activation. The frontal association and anterior cingulate cortices, subiculum, and vestibular areas are included showing that both HOM and HETzQ175 differ from wild-type in the activation of these brain areas in response to the odor of almond. HETzQ175 mice show nine brain area that differs from $\mathrm{HOMzQ175}$. Included are all hypothalamic areas, both primary and secondary somatosensory cortices and glomerular layer of the olfactory bulb.

Since the provocation paradigm for these patterns of brain activation was the odor of almond, the primary olfactory system was reconstructed in 3D as shown in Figure 5. Shown below are the $3 \mathrm{D}$ activation maps for each of the genotypes. As in Figure 4 the red depicts the localization of the average significant change in BOLD signal change for wild-type, HETzQ175, and HOMzQ175 mice. These same data are presented as activation maps in $2 \mathrm{D}$ axial sections shown in Figure 6. The most conspicuous difference between genotypes is the absence of BOLD activation in the glomerular layer of the olfactory bulb confirmed in Table 1.

Shown in Figure 7 are time-course data depicting the change in BOLD signal intensity in the glomerular layer of the olfactory bulb for wild-type, HETzQ175, and HOMzQ175 mice. Each mouse in the wild-type $(n=9)$ and HETzQ175 $(n=9)$ showed a significant change in BOLD signal intensity over time while two of the eight HOMzQ175 mice showed no activation. A repeated measures one-way ANOVA showed no significant main effect for genotype $(p=0.067)$ but did show a differential effect of genotype on BOLD response following presentation of almond odor [genotype $\times$ time: $F_{(2,138)}=1.45 p=0.0007$ ]. 
Table 2 | Brain volumes

Region of interest (ROI)

\begin{tabular}{|c|c|c|c|c|c|c|c|c|c|c|}
\hline & & & & & & \multirow[b]{2}{*}{$p$ Value } \\
\hline & $\bar{X}$ Vol mm & $\bar{X}$ Vox \# & SE & $\bar{X}$ Vol mm & $\bar{X}$ Vox \# & SE & $\bar{X}$ Vol mm & $\bar{X}$ Vox \# & SE & \\
\hline Caudate putamen & 17.6 & 1171 & 102.9 & 19.6 & 1304 & 93.1 & 14.8 & 387 & 93.8 & 0.03 \\
\hline Caudal piriform ctx & 5.9 & 392 & 35.7 & 6.5 & 435 & 31.5 & 4.9 & 325 & 33.5 & 0.03 \\
\hline Endopiriform area & 1.0 & 67 & 7.6 & 1.2 & 78 & 6.5 & 0.8 & 54 & 6.4 & 0.03 \\
\hline Anterior cingulate area & 2.8 & 186 & 18.5 & 3.2 & 213 & 16.3 & 2.4 & 158 & 16.6 & 0.03 \\
\hline Fimbria hippocampus & 1.8 & 123 & 11.8 & 2.1 & 139 & 10.3 & 1.5 & 102 & 11.4 & 0.03 \\
\hline Globus pallidus & 2.7 & 180 & 18.0 & 3.0 & $2 \mathrm{Cl} 1$ & 15.1 & 2.2 & 147 & 15.4 & 0.03 \\
\hline Primary somatosensory ctx & 20.7 & 1381 & 127.2 & 22.9 & 1528 & 109.8 & 17.4 & 1158 & 116.0 & 0.03 \\
\hline Superior colliculus & 8.3 & 551 & 48.4 & 9.3 & 618 & 43.3 & 6.9 & 458 & 43.7 & 0.03 \\
\hline Median raphe area & 1.3 & 86 & 7.2 & 1.5 & 97 & 6.8 & 1.1 & 73 & 6.2 & 0.03 \\
\hline Substantia nigra & 1.6 & 109 & 10.1 & 1.8 & 119 & 7.8 & 1.4 & 90 & 9.0 & 0.03 \\
\hline Parietal ctx & 0.5 & 31 & 2.6 & 0.6 & 37 & 3.4 & 0.3 & 23 & 3.1 & 0.03 \\
\hline Prelimbic ctx & 1.7 & 112 & 10.9 & 1.9 & 126 & 9.3 & 1.4 & 96 & 9.8 & 0.03 \\
\hline CA1 hippocampus & 8.0 & 536 & 47.6 & 8.9 & 590 & 42.2 & 6.8 & 454 & 43.4 & 0.03 \\
\hline Entorhinal ctx & 16.0 & 1066 & 93.1 & 17.7 & 1180 & 82.2 & 13.5 & 303 & 93.8 & 0.04 \\
\hline Olfactory tubercles & 1.8 & 120 & 11.5 & 2.0 & 136 & 11.5 & 1.5 & 99 & 10.4 & 0.04 \\
\hline Ventral medial hypothalamic area & 0.7 & 43 & 4.6 & 0.9 & 57 & 4.4 & 0.6 & 39 & 4.3 & 0.04 \\
\hline Medial geniculate & 1.3 & 87 & 8.3 & 1.5 & 97 & 6.6 & 1.1 & 72 & 6.7 & 0.04 \\
\hline Retrosplenial caudal ctx & 4.3 & 285 & 25.4 & 4.7 & 312 & 23.4 & 3.5 & 233 & 24.2 & 0.04 \\
\hline Ventral pallidum & 1.9 & 128 & 13.2 & 2.2 & 144 & 11.5 & 1.6 & 107 & 11.7 & 0.04 \\
\hline Auditory ctx & 3.8 & 256 & 24.2 & 4.4 & 290 & 20.4 & 3.2 & 216 & 23.0 & 0.04 \\
\hline Medial amygdaloid area & 2.0 & 132 & 12.7 & 2.2 & 149 & 11.2 & 1.7 & 111 & 10.7 & 0.04 \\
\hline Dentate gyrus & 6.3 & 420 & 38.4 & 6.9 & 460 & 34.0 & 5.2 & 347 & 37.4 & 0.04 \\
\hline Lateral geniculate & 0.7 & 46 & 4.2 & 0.8 & 52 & 4.1 & 0.5 & 36 & 3.7 & 0.04 \\
\hline Basal amygdaloid area & 3.1 & 206 & 20.2 & 3.5 & 230 & 18.2 & 2.6 & 173 & 17.8 & 0.04 \\
\hline Secondary somatosensory ctx & 5.6 & 370 & 34.1 & 6.1 & 407 & 30.9 & 4.6 & 308 & 31.5 & 0.04 \\
\hline Lateral rostral hypothalamic area & 2.9 & 191 & 17.3 & 3.2 & 214 & 15.3 & 2.4 & 160 & 17.1 & 0.04 \\
\hline Periaqueductal gray & 5.3 & 352 & 32.2 & 5.8 & 388 & 28.9 & 4.4 & 296 & 28.5 & 0.04 \\
\hline Central amygdaloid area & 1.8 & 122 & 11.4 & 2.0 & 133 & 9.7 & 1.5 & 103 & 10.3 & 0.04 \\
\hline Anterior hypothalamic area & 2.3 & 152 & 13.1 & 2.5 & 169 & 11.3 & 2.0 & 131 & 12.1 & 0.04 \\
\hline Insular rostral ctx & 5.9 & 392 & 34.4 & 6.5 & 431 & 31.6 & 4.9 & 326 & 32.7 & 0.04 \\
\hline Mesencephalic reticular formation & 6.9 & 458 & 42.0 & 7.5 & 503 & 34.3 & 5.7 & 383 & 37.3 & 0.04 \\
\hline Ventral tegmental area & 0.6 & 39 & 4.4 & 0.6 & 42 & 2.9 & 0.5 & 31 & 3.5 & 0.04 \\
\hline Subiculum & 7.2 & 478 & 44.3 & 7.9 & 525 & 37.4 & 6.0 & 399 & 33.1 & 0.04 \\
\hline Ventral thalamic area & 4.9 & 328 & 28.6 & 5.5 & 364 & 26.9 & 4.2 & 278 & 27.5 & 0.04 \\
\hline Inferior colliculus & 6.5 & 436 & 40.8 & 7.2 & 482 & 34.2 & 5.6 & 370 & 36.6 & 0.05 \\
\hline Orbital ctx & 5.5 & 367 & 33.2 & 6.1 & 407 & 29.6 & 4.7 & 311 & 30.4 & 0.05 \\
\hline CAS hippocampus & 3.4 & 225 & 21.9 & 3.8 & 251 & 19.1 & 2.8 & 185 & 20.1 & 0.05 \\
\hline Rostral piriform ctx & 8.1 & 540 & 47.9 & 8.9 & 590 & 42.8 & 6.7 & 443 & 47.0 & 0.05 \\
\hline Visual 1 ctx & 13.6 & 303 & 82.6 & 14.7 & 378 & 69.4 & 11.6 & 773 & 75.9 & 0.05 \\
\hline Dorsal raphe & 0.6 & 37 & 3.5 & 0.6 & 40 & 3.0 & 0.5 & 31 & 3.0 & 0.05 \\
\hline Primary motor ctx & 5.1 & 337 & 32.6 & 5.7 & 377 & 30.6 & 4.3 & 287 & 31.7 & 0.05 \\
\hline Paraventricular hypothalamic area & 0.2 & 10 & 1.4 & 0.2 & 12 & 1.1 & 0.1 & 8 & 1.2 & 0.05 \\
\hline Pituitary & 0.9 & 57 & 6.4 & 1.0 & 68 & 5.4 & 0.7 & 48 & 5.4 & 0.06 \\
\hline
\end{tabular}

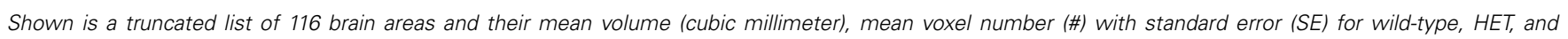

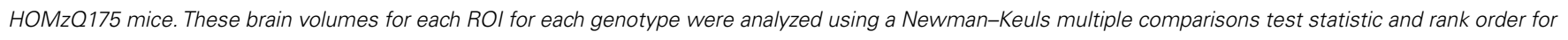

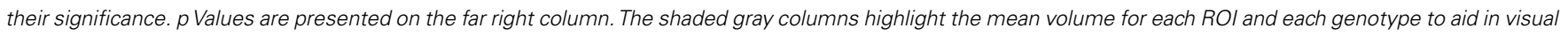
comparisons.

Shown in Figure 8 are changes in BOLD signal over time in response to $5 \% \mathrm{CO}_{2}$ challenge for wild-type $(n=7)$, HETzQ175 $(n=7)$, and HOMzQ175 $(n=10)$ mice. For both wild-type and
HETzQ175 conditions, one out of the seven animals did not response to $\mathrm{CO}_{2}$ challenge, i.e., no activated voxels in the primary somatosensory cortex, while 4 out of the 10 animals in 


\section{Huntington Neural Circuit of Dysregulation}
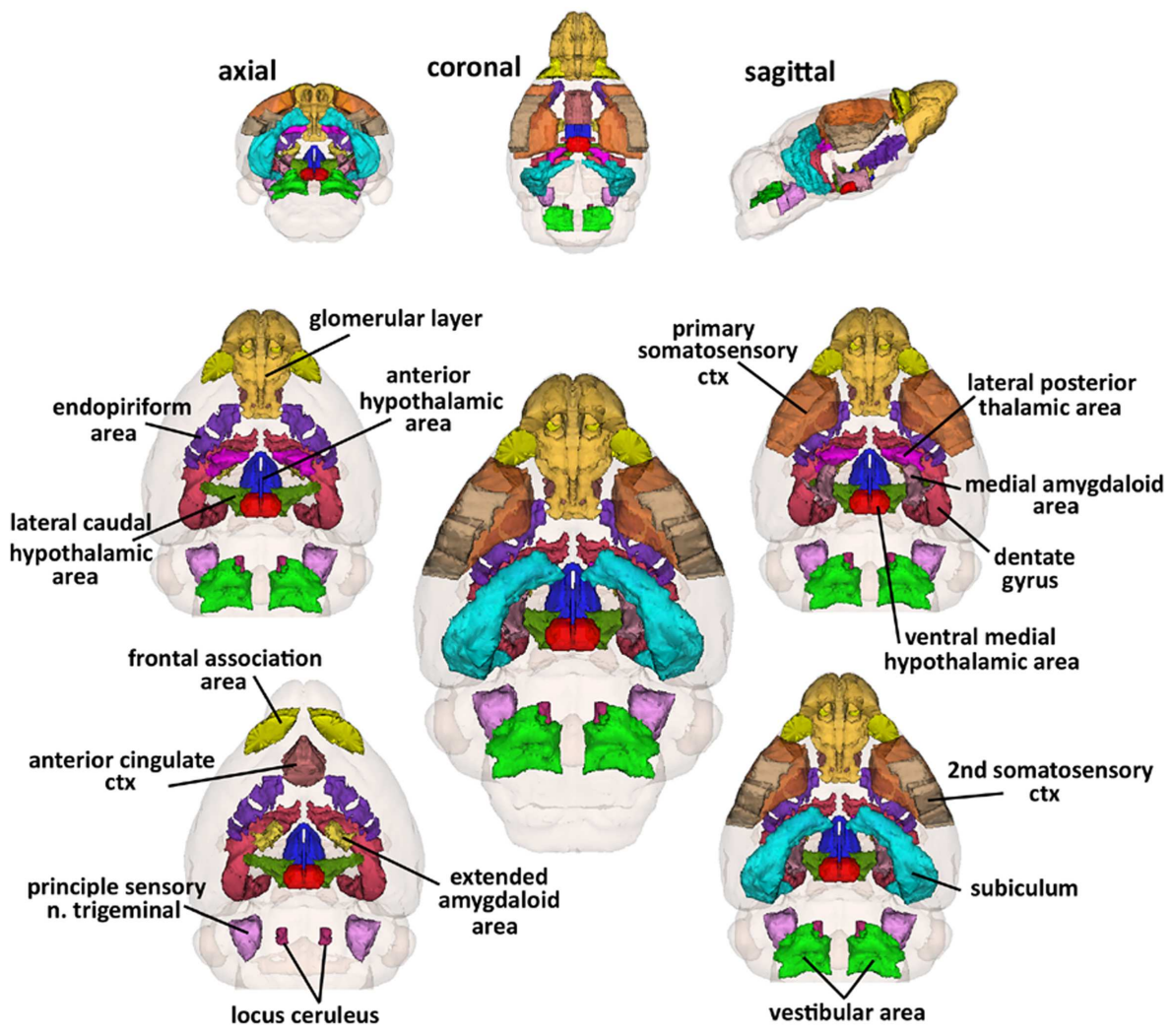

FIGURE 3 | Huntington neural circuit of dysregulation in response to almond odor. The 17, color-coded and labeled 3D volumes shown above were identified from 116 brain areas in the mouse atlas as having a significantly different BOLD signal between genotypes in response to the odor of almond. These areas are listed in Table 1. The central image is a coronal view of a translucent shell of the brain showing the total composite and location of the different 3D volumes of interest. Surrounding this are different layers of the neural circuit showing a caudal (deepest) to dorsal perspective of the different brain volumes. The panels on the top show the neural circuit in different orthogonal directions. the HOMzQ175 genotype did not respond to $\mathrm{CO}_{2}$ challenge. A repeated measures one-way ANOVA demonstrated that the timecourse of BOLD responses to $\mathrm{CO}_{2}$ differed by genotype [genotype $\times$ time: $\left.F_{(2,98)}=1.65, p=0.001\right]$. Post hoc pairwise comparisons at each repetition indicated that the differential effect of genotype on BOLD response occurred in the first five repetitions (30 s) following onset of the $\mathrm{CO}_{2}$ challenge. HOMzQ175 rats displayed diminished BOLD responses compared to both wild-type and HETzQ175 rats during repetitions 26-30 $(p<0.05$ for all comparisons).

Shown in Table 2 are the comparisons in brain volumes across wild-type, HET, and HOMzQ175 mice. The brain areas are rank order for their significance and are truncated from a larger list of 116 regions of activation (for complete list see Table S2 in Supplementary Material). The multiple comparison analysis showed 46 brain areas to differ significantly in volume across phenotypes. Post hoc analysis using Fisher's PLSD showed that the significant differences $(p<0.05)$ were all between the HET and HOMzQ175 mice and not between wild-type vs. HET or wild-type vs. HOMzQ175 mice.

\section{DISCUSSION}

We chose to challenge wild-type, HET, and HOMzQ175 mice with the smell of almond as a means of differentiating their brain activity toward a stimulus with a high emotional and motivational valence. In human and animal fMRI studies, desirable foods have been identified as motivating/rewarding stimuli activating limbic areas, particularly the orbital frontal, cingulate and insular cortices, amygdala, and striatum $(10,19-22)$. In a recent study, we were able to show that rats possess an innate sensitivity to energy rich food (such as almonds) and that this results in neural activation of the olfactory system and its connections to other brain areas (10). In a pilot study using serial dilutions of $100 \%$ benzaldehyde (almond odor), we identified a threshold dilution (1/10,000 v/v) that gave a robust and consistent pattern of brain activity to wildtype and HET Q175 mice, while the responsiveness of HOM Q175 was less (Figures 6 and 7) particularly in the glomerular layer of the olfactory bulb (Figure 4; Table 1).

Loss in olfactory discrimination and detection sensitivity are common with HD (23-26) and may appear prior to significant motor or cognitive dysfunction (27). Individuals at risk for HD, 


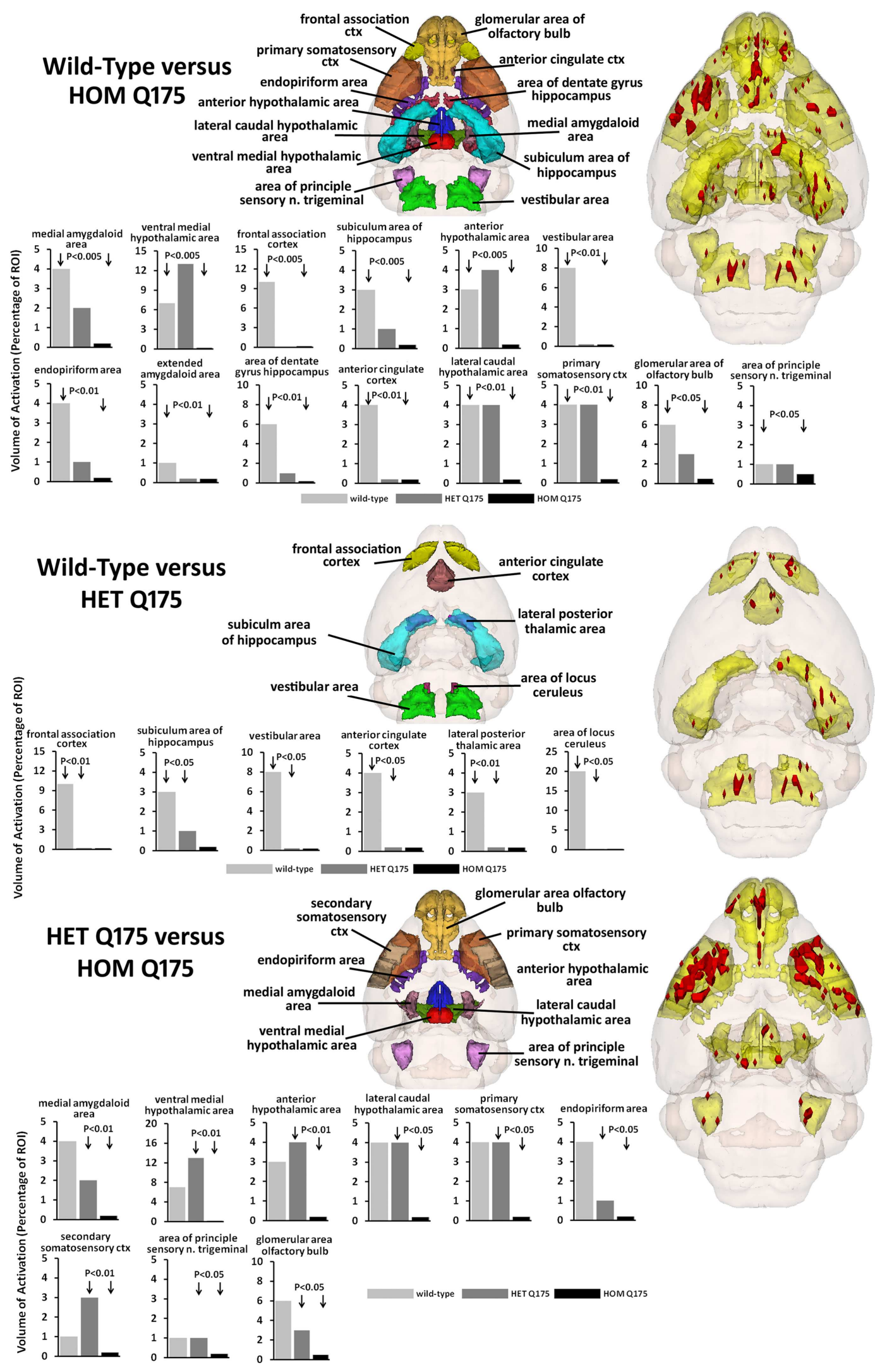

FIGURE 4 | Gene-dose effect in response to almond odor 


\section{FIGURE 4 | Continued}

The figure is parsed into three panels based on the significant differences between wild-type and $\mathrm{HOMzQ} 175$ (top panel), wild-type and HETzQ175 (middle panel), and HETzQ175 and HOMzQ175 (lower panel). Areas that are significantly different for each comparison are presented as 3D color-coded and labeled maps above with the individual bars graphs for each brain area below. These 3D color-coded volumes are coalesced into a single yellow volume to the right of each panel showing the location of the average, significant change in BOLD signal (red). These $3 \mathrm{D}$ activation maps are data taken from wild-type $(n=9)$ for the top and middle panels. The 3D activation map in the bottom panel is data taken from HETzQ175 $(n=9)$. The bar graphs show the volume of activation as a percentage of the brain area volume for each statistical comparison using Mann-Whitney U-test.

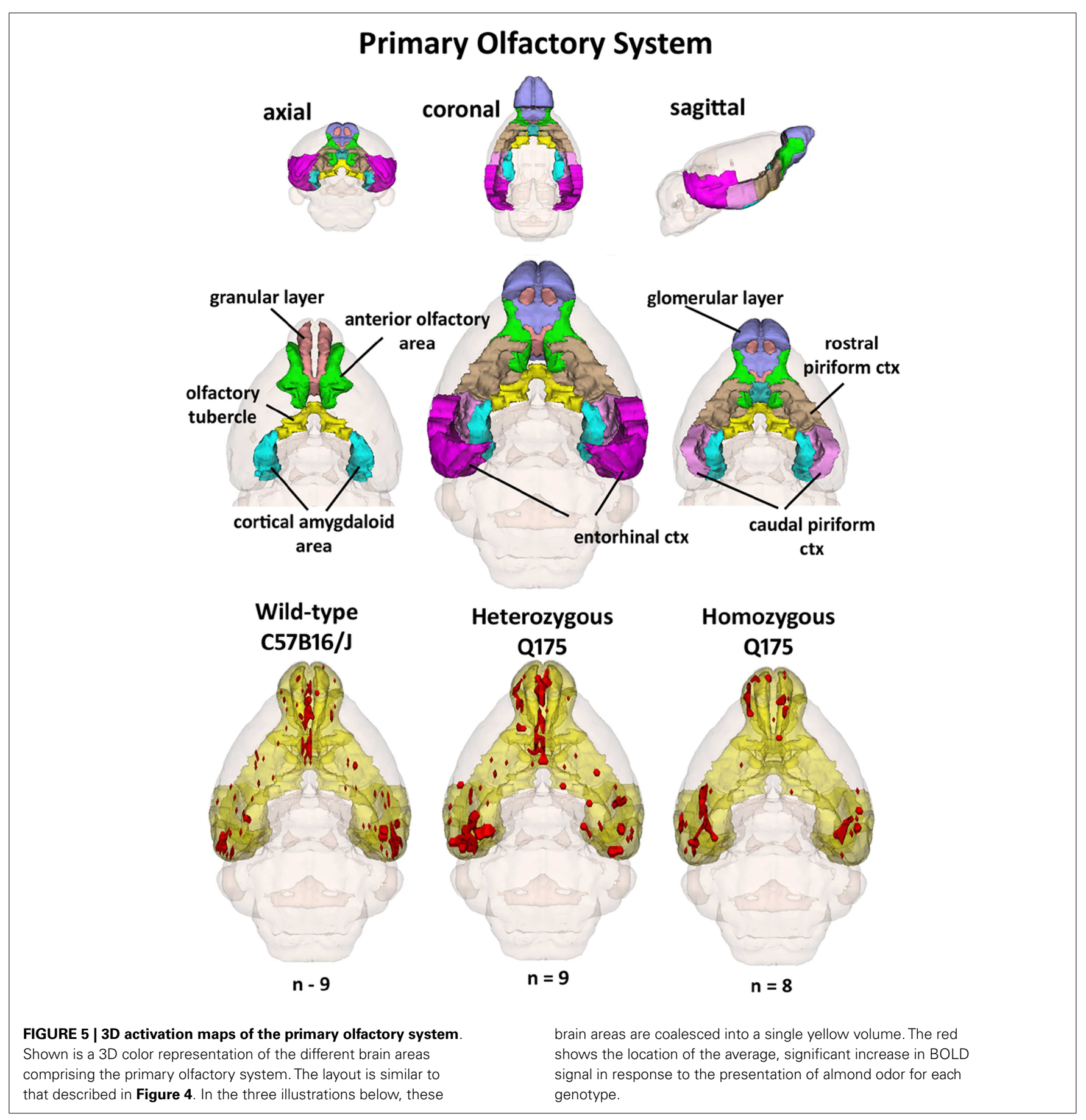




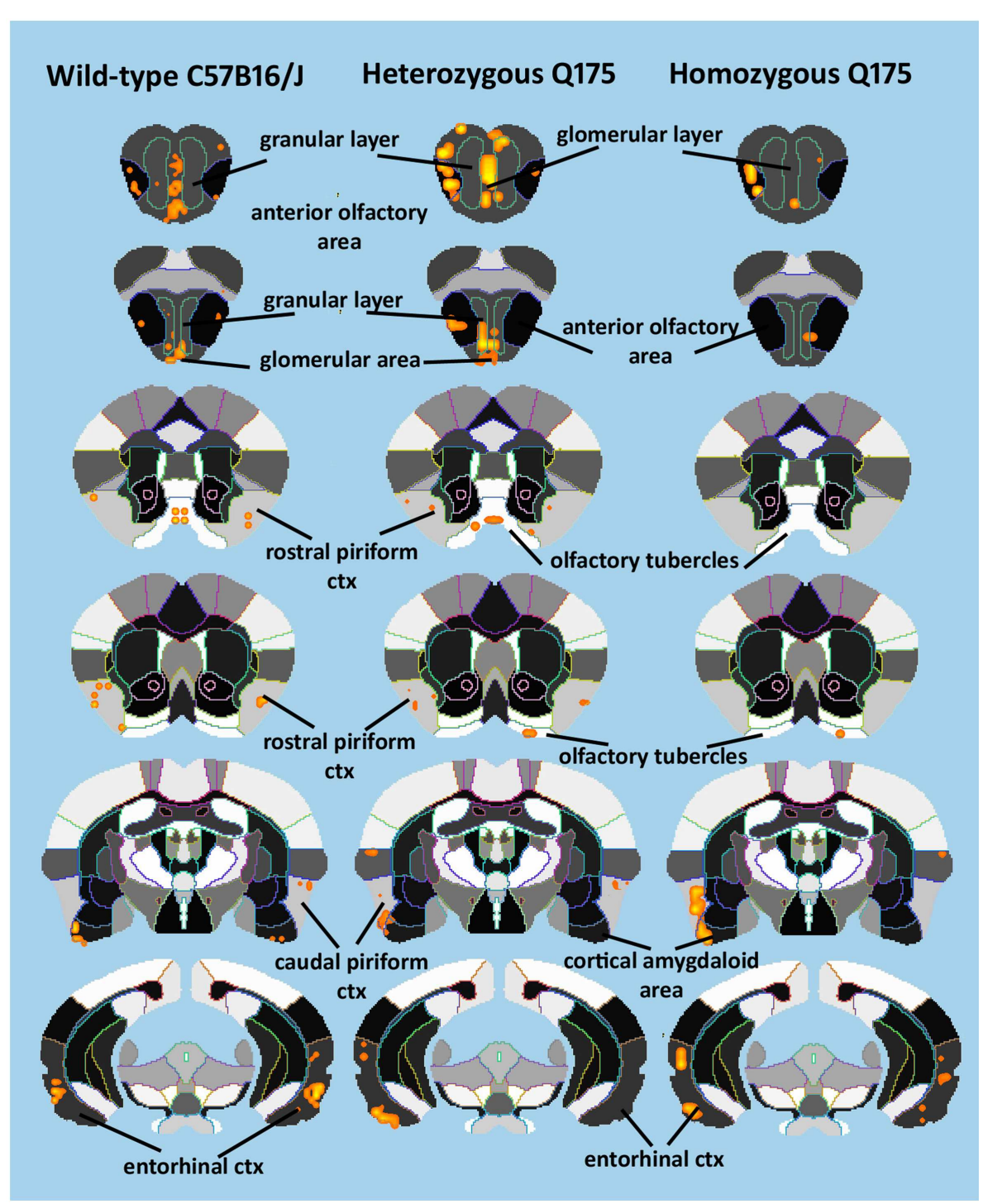

FIGURE 6 | 2D activation maps of the primary olfactory system. Shown are rostral (top) to caudal (bottom) axial sections taken from the mouse brain atlas and the location of the average, significant increase in BOLD signal for each genotype in response to the odor of almond. These are the same data shown in figure but with a 2D perspective to shown the signal location with the $3 \mathrm{D}$ volume. show a dysfunction in source memory for olfaction, i.e., the context associated with the memory (28). Transgenic mouse models of HD shows micro-aggregates of huntingtin proteins in primary olfactory system (29) and a reduction in structural neuroplasticity in olfactory cortex that may be causally related to the impairment in olfactory memory (24). These abnormalities may have contributed to the functional differences observed in the present study although imaging these phenotypes at 1 year of age preclude us from drawing any conclusions about olfaction as a biomarker of pre-symptomatic HD.

The imaging data suggest a "gene-dose effect," i.e., HETzQ175 mice show a reduction in brain activity from wild-type that is further reduced in HOMzQ175 mice. Indeed, of the 17 brain areas identified as responding differently to almond odor across genotypes, HOMzQ175 showed the greatest differences between wild-type and HETzQ175. Since the HETzQ175 form of HD is most prevalent in the population and is characterized by slow disease progression transitioning from a pre-symptomatic to symptomatic phenotype, greater emphasis is placed on understanding the HETzQ175 genotype. Only 6 out of 17 areas identified in Figure 3 were different between wild-type and HETzQ175 mice. These included the frontal association cortex, anterior cingulate cortex, subiculum of the hippocampus, lateral posterior thalamus and vestibular area, and locus coeruleus of the medulla oblongata. None of these areas were different between HETzQ175 and HOMzQ175 mice, so they represent brain areas deviating from the norm during disease progression and antecedent to any HD phenotype in the HETzQ175 mouse model $(6,7)$. Interestingly, 


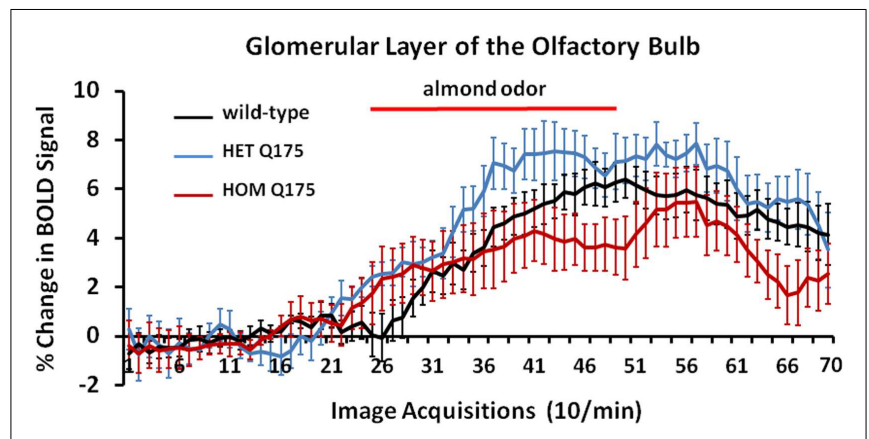

FIGURE 7 | Blood oxygen level dependent signal change over time in response to almond odor. Shown are the changes in the BOLD signal in the glomerulus of the olfactory bulb for each genotype in response to the presentation of almond odor following a 2 min baseline of 20 image acquisitions. While the time series are similar in that each genotype shows a comparable baseline and onset of activation there is a significant difference between the time series and an interaction between the time series and genotypes as shown in the two-way repeated measures ANOVA. Each time point is the mean BOLD signal \pm SEM.

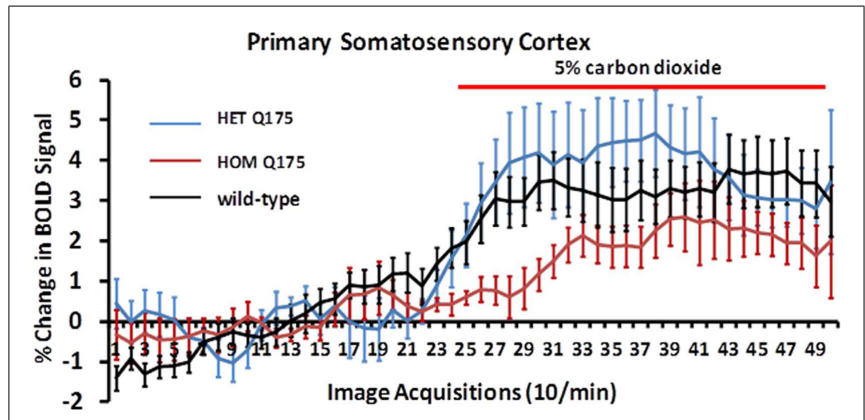

FIGURE 8 | Blood oxygen level dependent signal change to carbon dioxide challenge. Shown are time-course data for each genotype for the percentage change in BOLD signal intensity in the somatosensory cortex in response to the challenge of $5 \%$ carbon dioxide. Each image acquisition is the mean \pm SEM

the frontal association and cingulate cortices were shown to have reduced metabolic activity based on 2DG autoradiography in the R6/2 mouse model of HD (30).

In HD, striatal and cortical atrophy are the most common findings, and they correlate with cognitive deficits in attention, working memory, and executive functions (2). Cognitive decline is a well documented sign of early HD (31) even affecting individual at risk for $\mathrm{HD}$ (32-34). A time-dependent and gene-dose dependent change in cognitive function is a common feature of transgenic mouse models of $\operatorname{HD}(6,7,35-38)$. In wild-type mice, activation of subcortical and cortical brain areas identified with quantitative autoradiography for 2DG involve time-dependent changes in brain activity associated with memory consolidation. These brain areas include frontal association cortex, anterior cingulate, sensory motor cortices together with thalamus and hippocampus (39). All of these areas are represented in the brain map shown in Figure 3 reflecting areas differing in odor-induced activation across genotypes. Transgenic mouse models of HD suggest dysfunction in hippocampal dependent short term memory (40) and increased activity in local field potentials in the subiculum, dentate gyrus, and temporal cortex with an enhanced susceptibility to autogenic seizures (30). Neurotransmission between cortical and subcortical areas is affected in HD. Alterations in dendritic spine survival and density in cortical neurons characteristic of mouse model of HD accompany early symptoms of HD (41). There is also evidence that altered excitatory and inhibitory inputs to pyramidal neurons in the cortex are characteristics of disease progression in various mouse models of $\mathrm{HD}$, which points to early signs of synaptic dysregulation involving glutamate and GABA signaling $(42,43)$.

Changes in brain morphology and reduced brain volume, particularly in the area of the striatum and cortex are common features of disease progression in HD (44-46). Studies in mouse models of HD mice also report significant volume loss in the striatum, and neocortex as compared to wild-type (30,47-49). In our studies, the use of the $3 \mathrm{D}$ segmented atlas to calculate the average volume for 116 different brain areas across wild-type, HETzQ175, and HOMzQ175 mice corroborated what has been reported by Heikkinen and coworkers for striatal volumes across genotypes in zQ175 mice (7). At 10 months of age HOMzQ175 mice show a striatal volume (caudate/putamen) of just under $16 \mathrm{~mm}^{3}$ as compared to a wild-type of volume of just under $19 \mathrm{~mm}^{3}$, a decrease of ca. $15 \%$. In these studies, we report striatal volume of ca. $15 \mathrm{~mm}^{3}$ for HOMzQ175 and ca. $18 \mathrm{~mm}^{3}$ for wild-type or about a $17 \%$ reduction in volume. The major difference between studies is that we did not observe a reduction in ROI volumes in HETzQ175 mice. Indeed, there were no significant differences in ROI volumes between wild-type and HETzQ175 mice.

One of the more interesting aspects of this study is the presentation of almond odor, to "odor naïve" animals differing only in the protein expression of the single huntingtin gene. From 116 different brain areas, only 17 were found to differ in their activity when comparing wild-type, HETzQ175, and HOMzQ175 genotypes as shown in Figure 3. When viewed in the context of an integrated neural circuit, the areas of activation do not comprise a distinguishing "finger print" of brain function, e.g., motivation and reinforcement, pain, fear, or any particular neurochemical signaling pathway like dopamine or serotonin. Indeed, the caudate/putamen, thalamus, CA3 and CA1 of the hippocampus and much of the cortex are targeted areas in HD showing dramatic changes in function and morphology with disease progression. Yet, these areas were not identified with this almond odor provocation paradigm. What then is the connection, if any, between the glomerulus of the olfactory bulb, frontal association cortex, and anterior cingulate in the rostral part of the brain to the vestibular area, spinal trigeminal nucleus, and locus coeruleus in the most caudal part of the brain and the hypothalamus and amygdala in between? The answer may be found in a study by Fujinaga and coworkers mapping the neuroanatomical distribution of HAP1 mRNA in the male mouse brain (50). HAP1 can complex with Htt protein in the cytoplasm of neurons. Together, they regulate autophagosome transport, bidirectional movement of vesicles along the neuron axis involved in degradation of cellular debris (51). The presence of mutant HTT protein or reduction in HAP1 can impair the Htt/HAP1 interaction and disrupt autophagosome transport potentially leading to neuronal death (51). However, 
there are multiple lines of evidence that HAP1 is not contributing to the neuropathology of mutant Htt (52-54); instead, mutant Htt may be impacting the normal function of HAP1 $(55,56)$. To this point, HAP1 is not found in CA3/CA1 of hippocampus, thalamus, or much of the cortical mantel with only small amounts in the somatosensory cortex and caudate/putamen. Instead, its highest concentrations are found in a majority of those areas identified in Figure 3. Hence, the brain activity across wild-type, HETzQ175, and HOMzQ175, differentiated by the odor of almond, maps onto the neuroanatomical localization of HAP1. Might there be some functional relevance to this observation?

While HAP1 has been shown to function in intracellular trafficking of pro-brain-derived-neurotrophic factor $(57,58)$, epidermal growth factor (59), and gamma-aminobutyric acid type A receptor $(60)$, to note a few, it also directly impacts animal behavior via the hypothalamus. It was proposed by Chan and coworkers that this putative neural circuit connected by HAP1 expressing neurons functions in the control of instinctual behaviors, e.g., feeding, sex, and aggression, that involve autonomic and neuroendocrine processes (53). This notion was supported by the finding that transgenic mice deficient in HAP1, suffer from postnatal malnutrition and morbidity because of a dysfunction in feeding behavior. The link between HAP1 and feeding behavior was subsequently corroborated by others $(56,61)$. Given the odor stimulant used in the present study (almond) is intrinsically rewarding, there may be a causal link between the pattern of BOLD activation that differentiates the wild-type and HD genotypes, to the neuroanatomical localization of HAP1.

\section{CAVEATS AND DATA INTERPRETATION}

For any imaging study on awake animals, the issues and consequences related to the stress of head restraint and restricted body movement must be considered. Protocols have been developed to help lessen the stress of an imaging study by acclimating animals to the environment of the MR scanner and the restraining devices helping to reduce stress hormones levels and measures of sympathetic autonomic activity $(12,62)$. These acclimation procedures put animals through several simulated imaging sessions and have been used to study sexual arousal in monkeys (63), generalized seizures in rats and monkeys $(64,65)$, and exposure to psychostimulants like cocaine (66-68), nicotine (69), and apomorphine $(62,70)$. Nonetheless, one must consider the experimental confound that exists with low levels of arousal and stress associated with imaging awake animals. Indeed, the different phenotypes in this study may have very different sensitivities to restraint stress.

Another consideration when interpreting the data is the morphological changes in brain structure that occur over time in wild-type, HET, and HOMzQ175 mice as noted above. This raises the possibility that regional differences in brain volume in HOMzQ175 may have influenced the BOLD signal analysis particularly when the data is reported as volume of activation, i.e., number of voxels activated in a 3D brain volume. To control for this possibility, we normalized the volume of activation to the brain volume of interest for each subject prior to statistical comparisons for all three genotypes.

The data in Figure 8 clearly show that the HOMzQ175 have diminished vascular responsivity to $\mathrm{CO}_{2}$ challenge. This raises the possibility that the blunted BOLD response in HOMzQ175 mice may be due to ineffective coupling of blood/flow and metabolism. Cepeda-Prado and coworkers (30) using measures of cerebral blood volume (CBV) correlated with neuronal excitability, suggest there is normal neurovascular coupling in HD mice, but a paradoxical decrease in metabolism with very high CBV suggestive of impaired neurometabolic coupling. The implications are far reaching and may underscore a mechanism that contributes to loss of cognitive function with disease severity. There are no reports in the human or animal imaging literature that we know of that show challenges with $\mathrm{CO}_{2}$.

\section{SUMMARY}

The prospective capability of animal imaging to follow changes in brain neurobiology following genetic or environmental insult has great value in the field of HD research as one can follow the etiology and pathophysiology of disease progression. In addition, the combination of awake fMRI in mice with an imaging genetics approach (71) represents a powerful experimental strategy that permits the identification of the affect of single gene mutations on neural circuits regulating emotion and cognition. While imaging genetics in humans takes advantage of natural polymorphisms to examine the genetic basis of differences in neural activation, imaging genetics in transgenic animals is a more targeted approach that offers the potential to investigate the contribution of a single gene to neural response patterns. When this neural activity is combined with a 3D segmented, annotated MRI mouse atlas it is possible to reconstruct distributed integrated neural circuits both in $3 \mathrm{D}$ and $2 \mathrm{D}$ that "finger print" the pattern of brain activity to a provocation paradigm as is the case here.

\section{ACKNOWLEDGMENTS}

The authors thank Psychogenics Inc., Tarrytown, NY, USA for the KI mice. Funding - this work was sponsored by Ekam Imaging.

\section{SUPPLEMENTARY MATERIAL}

The Supplementary Material for this article can be found online at http://www.frontiersin.org/Journal/10.3389/fneur.2014.00094/ abstract

\section{REFERENCES}

1. Montoya A, Pelletier M, Menear M, Duplessis E, Richer F, Lepage M. Episodic memory impairment in Huntington's disease: a meta-analysis. Neuropsychologia (2006) 44(10):1984-94. doi:10.1016/j.neuropsychologia.2006.01.015

2. Montoya A, Price BH, Menear M, Lepage M. Brain imaging and cognitive dysfunctions in Huntington's disease. J Psychiatry Neurosci (2006) 31(1):21-9.

3. Rosenblatt A, Leroi I. Neuropsychiatry of Huntington's disease and other basal ganglia disorders. Psychosomatics (2000) 41(1):24-30. doi:10.1016/S00333182(00)71170-4

4. Enzi B, Edel MA, Lissek S, Peters S, Hoffmann R, Nicolas V, et al. Altered ventral striatal activation during reward and punishment processing in premanifest Huntington's disease: a functional magnetic resonance study. Exp Neurol (2012) 235(1):256-64. doi:10.1016/j.expneurol.2012.02.003

5. Ferris CF, Smerkers B, Kulkarni P, Caffrey M, Afacan O, Toddes S, et al. Functional magnetic resonance imaging in awake animals. Rev Neurosci (2011) 22(6):665-74. doi:10.1515/RNS.2011.050

6. Menalled LB, Kudwa AE, Miller S, Fitzpatrick J, Watson-Johnson J, Keating N, et al. Comprehensive behavioral and molecular characterization of a new knockin mouse model of Huntington's disease: zQ175. PLoS One (2012) 7(12):e49838. doi:10.1371/journal.pone.0049838 
7. Heikkinen T, Lehtimaki K, Vartiainen N, Puolivali J, Hendricks SJ, Glaser JR, et al. Characterization of neurophysiological and behavioral changes, MRI brain volumetry and 1H MRS in zQ175 knock-in mouse model of Huntington's disease. PLoS One (2012) 7(12):e50717. doi:10.1371/journal.pone.0050717

8. Heng MY, Tallaksen-Greene SJ, Detloff PJ, Albin RL. Longitudinal evaluation of the Hdh(CAG) 150 knock-in murine model of Huntington's disease. J Neurosci (2007) 27(34):8989-98. doi:10.1523/JNEUROSCI.1830-07.2007

9. Heng MY, Detloff PJ, Paulson HL, Albin RL. Early alterations of autophagy in Huntington disease-like mice. Autophagy (2010) 6(8):1206-8. doi:10.4161/auto. 6.8.13617

10. Kulkarni P, Stolberg T, Sullivanjr JM, Ferris CF. Imaging evolutionarily conserved neural networks: preferential activation of the olfactory system by foodrelated odor. Behav Brain Res (2012) 230(1):201-7. doi:10.1016/j.bbr.2012.02. 002

11. Desai M, Kahn I, Knoblich U, Bernstein J, Atallah H, Yang A, et al. Mapping brain networks in awake mice using combined optical neural control and fMRI. J Neurophysiol (2011) 105(3):1393-405. doi:10.1152/jn.00828.2010

12. King JA, Garelick TS, Brevard ME, Chen W, Messenger TL, Duong TQ, et al. Procedure for minimizing stress for fMRI studies in conscious rats. J Neurosci Methods (2005) 148(2):154-60. doi:10.1016/j.jneumeth.2005.04.011

13. Norris DG. Principles of magnetic resonance assessment of brain function. J Magn Reson Imaging (2006) 23(6):794-807. doi:10.1002/jmri.20587

14. Duong TQ, Yacoub E, Adriany G, Hu X, Ugurbil K, Kim SG. Microvascular BOLD contribution at 4 and $7 \mathrm{~T}$ in the human brain: gradient-echo and spin-echo fMRI with suppression of blood effects. Magn Reson Med (2003) 49(6):1019-27. doi:10.1002/mrm.10472

15. Yacoub E, Shmuel A, Logothetis N, Ugurbil K. Robust detection of ocular dominance columns in humans using Hahn spin echo BOLD functional MRI at 7 Tesla. Neuroimage (2007) 37(4):1161-77. doi:10.1016/j.neuroimage.2007. 05.020

16. Zhang N, Yacoub E, Zhu XH, Ugurbil K, Chen W. Linearity of bloodoxygenation-level dependent signal at microvasculature. Neuroimage (2009) 48(2):313-8. doi:10.1016/j.neuroimage.2009.06.071

17. Brevard ME, Duong TQ, King JA, Ferris CF. Changes in MRI signal intensity during hypercapnic challenge under conscious and anesthetized conditions. Magn Reson Imaging (2003) 21(9):995-1001. doi:10.1016/S0730-725X(03)00204-2

18. Genovese CR, Lazar NA, Nichols T. Thresholding of statistical maps in functional neuroimaging using the false discovery rate. Neuroimage (2002) 15:870-8. doi:10.1006/nimg.2001.1037

19. Jacobson A, Green E, Murphy C. Age-related functional changes in gustatory and reward processing regions: an fMRI study. Neuroimage (2010) 53(2):602-10. doi:10.1016/j.neuroimage.2010.05.012

20. Grabenhorst F, Rolls ET, Parris BA, d'Souza AA. How the brain represents the reward value of fat in the mouth. Cereb Cortex (2010) 20(5):1082-91. doi:10.1093/cercor/bhp169

21. Bragulat V, Dzemidzic M, Bruno C, Cox CA, Talavage T, Considine RV, et al. Food-related odor probes of brain reward circuits during hunger: a pilot fMRI study. Obesity (Silver Spring) (2010) 18(8):1566-71. doi:10.1038/oby.2010.57

22. McCabe C, Rolls ET. Umami: a delicious flavor formed by convergence of taste and olfactory pathways in the human brain. Eur J Neurosci (2007) 25(6):1855-64. doi:10.1111/j.1460-9568.2007.05445.x

23. Nordin S, Paulsen JS, Murphy C. Sensory- and memory-mediated olfactory dysfunction in Huntington's disease. J Int Neuropsychol Soc (1995) 1(3):281-90. doi: $10.1017 /$ S1355617700000278

24. Lazic SE, Goodman AO, Grote HE, Blakemore C, Morton AJ, Hannan AJ, et al. Olfactory abnormalities in Huntington's disease: decreased plasticity in the primary olfactory cortex of R6/1 transgenic mice and reduced olfactory discrimination in patients. Brain Res (2007) 1151:219-26. doi:10.1016/j.brainres.2007. 03.018

25. Hamilton JM, Murphy C, Paulsen JS. Odor detection, learning, and memory in Huntington's disease. J Int Neuropsychol Soc (1999) 5(7):609-15. doi:10.1017/ S1355617799577035

26. Moberg PJ, Doty RL. Olfactory function in Huntington's disease patients and at-risk offspring. Int J Neurosci (1997) 89(1-2):133-9. doi:10.3109/ 00207459708988468

27. Larsson M, Lundin A, Robins Wahlin TB. Olfactory functions in asymptomatic carriers of the Huntington disease mutation. J Clin Exp Neuropsychol (2006) 28(8):1373-80. doi:10.1080/13803390500473746
28. Pirogovsky E, Gilbert PE, Jacobson M, Peavy G, Wetter S, Goldstein J, et al. Impairments in source memory for olfactory and visual stimuli in preclinical and clinical stages of Huntington's disease. J Clin Exp Neuropsychol (2007) 29(4):395-404. doi:10.1080/13803390600726829

29. Menalled LB, Sison JD, Dragatsis I, Zeitlin S, Chesselet MF. Time course of early motor and neuropathological anomalies in a knock-in mouse model of Huntington's disease with 140 CAG repeats. J Comp Neurol (2003) 465(1):11-26. doi:10.1002/cne.10776

30. Cepeda-Prado E, Popp S, Khan U, Stefanov D, Rodriguez J, Menalled LB, et al. R6/2 Huntington's disease mice develop early and progressive abnormal brain metabolism and seizures. J Neurosci (2012) 32(19):6456-67. doi:10.1523/ JNEUROSCI.0388-12.2012

31. Paulsen JS, Wang C, Duff K, Barker R, Nance M, Beglinger L, et al. Challenges assessing clinical endpoints in early Huntington disease. Mov Disord (2010) 25(15):2595-603. doi:10.1002/mds.23337

32. Beglinger LJ, O'Rourke JJ, Wang C, Langbehn DR, Duff K, Paulsen JS. Earliest functional declines in Huntington disease. Psychiatry Res (2010) 178(2):414-8. doi:10.1016/j.psychres.2010.04.030

33. Duff K, Paulsen J, Mills J, Beglinger LJ, Moser DJ, Smith MM, et al. Mild cognitive impairment in prediagnosed Huntington disease. Neurology (2010) 75(6):500-7. doi:10.1212/WNL.0b013e3181eccfa2

34. Paulsen JS, Smith MM, Long JD. Cognitive decline in prodromal Huntington disease: implications for clinical trials. J Neurol Neurosurg Psychiatry (2013) 84(11):1233-9. doi:10.1136/jnnp-2013-305114

35. Fielding SA, Brooks SP, Klein A, Bayram-Weston Z, Jones L, Dunnett SB. Profiles of motor and cognitive impairment in the transgenic rat model of Huntington's disease. Brain Res Bull (2012) 88(2-3):223-36. doi:10.1016/j.brainresbull.2011. 09.011

36. Bayram-Weston Z, Jones L, Dunnett SB, Brooks SP. Light and electron microscopic characterization of the evolution of cellular pathology in YAC128 Huntington's disease transgenic mice. Brain Res Bull (2012) 88(2-3):137-47. doi:10.1016/j.brainresbull.2011.05.005

37. Brooks SP, Betteridge H, Trueman RC, Jones L, Dunnett SB. Selective extradimensional set shifting deficit in a knock-in mouse model of Huntington's disease. Brain Res Bull (2006) 69(4):452-7. doi:10.1016/j.brainresbull.2006.02.011

38. Lione LA, Carter RJ, Hunt MJ, Bates GP, Morton AJ, Dunnett SB. Selective discrimination learning impairments in mice expressing the human Huntington's disease mutation. J Neurosci (1999) 19(23):10428-37.

39. Sif J, Messier C, Meunier M, Bontempi B, Calas A, Destrade C. Time-dependent sequential increases in [14C]2-deoxyglucose uptake in subcortical and cortical structures during memory consolidation of an operant training in mice. Behav Neural Biol (1991) 56(1):43-61. doi:10.1016/0163-1047(91)90279-Y

40. Ransome MI, Hannan AJ. Behavioural state differentially engages septohippocampal cholinergic and GABAergic neurons in R6/1 Huntington's disease mice. Neurobiol Learn Mem (2012) 97(2):261-70. doi:10.1016/j.nlm.2012.01. 004

41. Murmu RP, Li W, Holtmaat A, Li JY. Dendritic spine instability leads to progressive neocortical spine loss in a mouse model of Huntington's disease. J Neurosci (2013) 33(32):12997-3009. doi:10.1523/JNEUROSCI.5284-12.2013

42. Cummings DM, Andre VM, Uzgil BO, Gee SM, Fisher YE, Cepeda C, et al. Alterations in cortical excitation and inhibition in genetic mouse models of Huntington's disease. J Neurosci (2009) 29(33):10371-86. doi:10.1523/JNEUROSCI. 1592-09.2009

43. Joshi PR, Wu NP, Andre VM, Cummings DM, Cepeda C, Joyce JA, et al. Age-dependent alterations of corticostriatal activity in the YAC128 mouse model of Huntington disease. J Neurosci (2009) 29(8):2414-27. doi:10.1523/ JNEUROSCI.5687-08.2009

44. Rosas HD, Koroshetz WJ, Chen YI, Skeuse C, Vangel M, Cudkowicz ME, et al. Evidence for more widespread cerebral pathology in early HD: an MRI-based morphometric analysis. Neurology (2003) 60(10):1615-20. doi:10.1212/01.WNL. $0000065888.88988 .6 \mathrm{E}$

45. Aylward EH, Anderson NB, Bylsma FW, Wagster MV, Barta PE, Sherr M, et al. Frontal lobe volume in patients with Huntington's disease. Neurology (1998) 50(1):252-8. doi:10.1212/WNL.50.1.252

46. Bohanna I, Georgiou-Karistianis N, Hannan AJ, Egan GF. Magnetic resonance imaging as an approach towards identifying neuropathological biomarkers for Huntington's disease. Brain Res Rev (2008) 58(1):209-25. doi:10.1016/j. brainresrev.2008.04.001 
47. Lerch JP, Carroll JB, Spring S, Bertram LN, Schwab C, Hayden MR, et al. Automated deformation analysis in the YAC128 Huntington disease mouse model. Neuroimage (2008) 39(1):32-9. doi:10.1016/j.neuroimage.2007.08.033

48. Sawiak SJ, Wood NI, Williams GB, Morton AJ, Carpenter TA. Voxel-based morphometry in the R6/2 transgenic mouse reveals differences between genotypes not seen with manual 2D morphometry. Neurobiol Dis (2009) 33(1):20-7. doi:10.1016/j.nbd.2008.09.016

49. Rattray I, Smith EJ, Crum WR, Walker TA, Gale R, Bates GP, et al. Correlations of behavioral deficits with brain pathology assessed through longitudinal MRI and histopathology in the R6/1 mouse model of Huntington's disease. PLoS One (2013) 8(12):e84726. doi:10.1371/journal.pone.0084726

50. Fujinaga R, Kawano J, Matsuzaki Y, Kamei K, Yanai A, Sheng Z, et al. Neuroanatomical distribution of huntingtin-associated protein 1-mRNA in the male mouse brain. J Comp Neurol (2004) 478(1):88-109. doi:10.1002/cne.20277

51. Wong YC, Holzbaur EL. The regulation of autophagosome dynamics by huntingtin and HAP1 is disrupted by expression of mutant huntingtin, leading to defective cargo degradation. J Neurosci (2014) 34(4):1293-305. doi:10.1523/ JNEUROSCI.1870-13.2014

52. Bertaux F, Sharp AH, Ross CA, Lehrach H, Bates GP, Wanker E. HAP1-huntingtin interactions do not contribute to the molecular pathology in Huntington's disease transgenic mice. FEBS Lett (1998) 426(2):229-32. doi:10.1016/S00145793(98)00352-4

53. Chan EY, Nasir J, Gutekunst CA, Coleman S, Maclean A, Maas A, et al. Targeted disruption of huntingtin-associated protein-1 (Hap1) results in postnatal death due to depressed feeding behavior. Hum Mol Genet (2002) 11(8):945-59. doi:10.1093/hmg/11.8.945

54. Li SH, Yu ZX, Li CL, Nguyen HP, Zhou YX, Deng C, et al. Lack of huntingtinassociated protein-1 causes neuronal death resembling hypothalamic degeneration in Huntington's disease. J Neurosci (2003) 23(17):6956-64.

55. Xiang J, Yang H, Zhao T, Sun M, Xu X, Zhou XF, et al. Huntingtin-associated protein 1 regulates postnatal neurogenesis and neurotrophin receptor sorting. J Clin Invest (2014) 124(1):85-98. doi:10.1172/JCI69206

56. Lin YF, Xu X, Cape A, Li S, Li XJ. Huntingtin-associated protein-1 deficiency in orexin-producing neurons impairs neuronal process extension and leads to abnormal behavior in mice. J Biol Chem (2010) 285(21):15941-9. doi:10.1074/jbc.M110.107318

57. Yang M, Lim Y, Li X, Zhong JH, Zhou XF. Precursor of brain-derived neurotrophic factor (proBDNF) forms a complex with huntingtin-associated protein-1 (HAP1) and sortilin that modulates proBDNF trafficking, degradation, and processing. J Biol Chem (2011) 286(18):16272-84. doi:10.1074/jbc. M110.195347

58. Wu LL, Fan Y, Li S, Li XJ, Zhou XF. Huntingtin-associated protein-1 interacts with pro-brain-derived neurotrophic factor and mediates its transport and release. J Biol Chem (2010) 285(8):5614-23. doi:10.1074/jbc.M109.073197

59. Li Y, Chin LS, Levey AI, Li L. Huntingtin-associated protein 1 interacts with hepatocyte growth factor-regulated tyrosine kinase substrate and functions in endosomal trafficking. J Biol Chem (2002) 277(31):28212-21. doi:10.1074/jbc. M111612200

60. Kittler JT, Thomas P, Tretter V, Bogdanov YD, Haucke V, Smart TG, et al. Huntingtin-associated protein 1 regulates inhibitory synaptic transmission by modulating gamma-aminobutyric acid type A receptor membrane trafficking. Proc Natl Acad Sci U S A (2004) 101(34):12736-41. doi:10.1073/pnas. 0401860101

61. Sheng G, Chang GQ, Lin JY, Yu ZX, Fang ZH, Rong J, et al. Hypothalamic huntingtin-associated protein 1 as a mediator of feeding behavior. Nat Med (2006) 12(5):526-33. doi:10.1038/nm1382
62. Zhang Z, Andersen AH, Avison MJ, Gerhardt GA, Gash DM. Functional MRI of apomorphine activation of the basal ganglia in awake rhesus monkeys. Brain Res (2000) 852(2):290-6. doi:10.1016/S0006-8993(99)02243-X

63. Ferris CF, Snowdon CT, King JA, Sullivan JM Jr, Ziegler TE, Olson DP, et al. Activation of neural pathways associated with sexual arousal in non-human primates. J Magn Reson Imaging (2004) 19(2):168-75. doi:10.1002/jmri.10456

64. Tenney JR, Duong TQ, King JA, Ludwig R, Ferris CF. Corticothalamic modulation during absence seizures: a functional MRI approach. Epilepsia (2003) 44:1133-40. doi:10.1046/j.1528-1157.2003.61002.x

65. Tenney JR, Brevard ME, King JA, Ferris CF. fMRI of generalized absence seizures in conscious marmoset monkeys reveals corticothalamic activation. Epilepsia (2004) 45:1240-7. doi:10.1111/j.0013-9580.2004.21504.x

66. Febo M, Segarra A, Nair G, Schmidt K, Duong T, Ferris C. The neural consequences of repeated cocaine exposure revealed by functional MRI in awake rats. Neuropsychopharmacology (2005) 25:1132-6.

67. Ferris CF, Kulkarni P, Sullivan MJJ, Harder JA, Messenger TL, Febo M. Pup suckling is more rewarding than cocaine: evidence from $\mathrm{fMRI}$ and $3 \mathrm{D}$ computational analyses. J Neurosci (2005) 25:149-56. doi:10.1523/JNEUROSCI.3156-04.2005

68. Febo M, Segarra AC, Tenney JR, Sullivan R, Brevard M, Duong TQ, et al. Imaging cocaine-induced changes in the reward system in conscous rate. J Neurosci Methods (2004) 139:167-76. doi:10.1016/j.jneumeth.2004.04.028

69. Skoubis PD, Hradil VP, Chin CL, Luo Y, Fox GB, McGaraughty S. Mapping brain activity following administration of a nicotinic acetylcholine receptor agonist, ABY-594, using functional magnetic resonance imaging in awake rats. Neuroscience (2006) 137:583-91. doi:10.1016/j.neuroscience.2005.08.072

70. Chin CL, Fox GB, Hradil VP, Osinski MA, McGaraughty SP, Skoubis PD, et al. Pharmacological MRI in awake rats reveals neural activity in area postrema and nucleus tractus solitarius: relevance as a potential biomarker for detecting druginduced emesis. Neuroimage (2006) 33:1152-60. doi:10.1016/j.neuroimage. 2006.06.059

71. Hariri AR, Drabant EM, Weinberger DR. Imaging genetics: perspectives from studies of genetically driven variation in serotonin function and corticolimbic affective processing. Biol Psychiatry (2006) 59(10):888-97. doi:10.1016/j. biopsych.2005.11.005

Conflict of Interest Statement: Craig Ferris, Mark Nedelman, and Praveen Kulkarni have a financial interest in Ekam Imaging and Ekam Solutions, the company that sponsored the research and developed the 3D segmented annotated mouse atlas. Craig Ferris and Steven Toddes have a financial interest in Animal Imaging Research, the company that makes the awake mouse imaging system. The other co-authors declare no conflicts of interest.

Received: 03 March 2014; accepted: 25 May 2014; published online: 30 June 2014. Citation: Ferris CF, Kulkarni P, Toddes S, Yee J, Kenkel W and Nedelman $M$ (2014) Studies on the Q175 knock-in model of Huntington's disease using functional imaging in awake mice: evidence of olfactory dysfunction. Front. Neurol. 5:94. doi: 10.3389/fneur.2014.00094

This article was submitted to Neurodegeneration, a section of the journal Frontiers in Neurology.

Copyright (c) 2014 Ferris, Kulkarni, Toddes, Yee, Kenkel and Nedelman. This is an open-access article distributed under the terms of the Creative Commons Attribution License (CC BY). The use, distribution or reproduction in other forums is permitted, provided the original author(s) or licensor are credited and that the original publication in this journal is cited, in accordance with accepted academic practice. No use, distribution or reproduction is permitted which does not comply with these terms. 